\title{
Isolation and Identification of Mycobacterium chelonae from Human Sputum among Suspected Pulmonary Tuberculosis Infections in Basra-Iraq
}

\author{
Abdulameer A. Al-Mussawi* \\ Nursing College / Basra University \\ *Corresponding author: dr_ameer2006@yahoo.com
}

Received December 12, 2014; Revised December 22, 2014; Accepted December 31, 2014

\begin{abstract}
Objective: The purpose of this study was to estimate the frequency of Mycobacterium Chelonae (M. chelonae) among tuberculosis suspected patients in Basra governorate and evaluate the antimicrobial susceptibility. Methods: Isolation of M. chelonae from 150 samples from patients attended to the Advisory Clinic for Chest Diseases and Respiratory (ACCDR) in Basra city, smears were stained with the Ziehl Neelsen technique. Specimens were inoculated on Lowenstein Jensen medium, Identification to species level was achieved on the basis of the growth characteristics. Drug susceptibility were tested to antibiotics (Rifampicin, Isoniazid, Ethambutol, Pyrazinamide and Streptomycin) using proportional method. Results: from 150 sputum samples among tuberculosis suspected patients, sixteen samples (10.6\%) were Nontuberculosis mycobacterium (NTM), from 16 NTM samples, 4 (2.6\%) were M. chelonae. Drug susceptibility results showed that all isolates resistance to rifampicin, while one isolate showed intermediate resistance to ethambutol. All isolates of $\mathrm{M}$. chelonae were sensitive to pyrazinamide, isoniazid and streptomycin. Conclusion: The M. chelonae present a high frequency, especially among tuberculosis suspected patients, which requires confirmation on a follow-up, along with the examination of patterns of sensitivity, is an absolute necessity in health centers in Iraq.
\end{abstract}

Keywords: mycobacterium chelonae, Non tuberculosis mycobacterium, Tuberculosis, TB, Antimicrobial Susceptibility Testing

Cite This Article: Abdulameer A. Al-Mussawi, "Isolation and Identification of Mycobacterium chelonae from Human Sputum among Suspected Pulmonary Tuberculosis Infections in Basra-Iraq.” American Journal of Infectious Diseases and Microbiology, vol. 2, no. 6 (2014): 145-148. doi: 10.12691/ajidm-2-6-2.

\section{Introduction}

Non-tuberculous mycobacteria (NTM) are ubiquitous organisms that rarely cause disease in immunocompetent individuals. NTM have been recovered in many parts of the world and from a variety of environmental reservoirs (Al-Sulami et al., 2012). There has been an increase in the incidence of infections caused by nontuberculous mycobacteria species during the last decades, especially in rapidly growing mycobacteria (RGM) (Sethi et al., 2003).

From a clinical viewpoint mainly RGM are opportunistic pathogens. The species most commonly recovered from patients belong to the Mycobacterium fortuitum complex, $M$. chelonae, $M$. abscessus, $M$. mucogenicum and $M$. smegmatis, reported almost everywhere worldwide. Occasionally other RGM species can cause disease in humans(García-Agudo and GarcíaMartos, 2011). RGM most commonly complicate lung disease due to previous mycobacterial disease, cystic fibrosis (CF), chronic obstructive pulmonary disease (COPD), malignancy, lipoid pneumonia, and conditions associated with chronic gastro esophageal reflux, or vomiting (Wali, 2009).
Pulmonary diseases are a common manifestation of RGM infections. and most are due to three species: $M$. abscessus, M. fortuitum, and M. chelonae. Of these, approximately $80 \%$ of chronic pulmonary diseases are caused by M. abscessus (Talip et al., 2013). M. chelonae, a RGM, also known as cold blooded tubercle bacillus originally isolated from a turtle (Grange, 1981). It is a member of Runyon group IV mycobacteria that are commonly isolated from water and soil. They are generally regarded as commensals in humans (Brown, 1985).

M. chelonae most commonly causes infection in immunocompromised patients (Falsey et al., 2013). It is one of the most common clinical picture is skin disease, sometimes scattered, usually in patients under immunosuppressive therapy for solid organ transplantation, rheumatoid arthritis or other autoimmune process. It can also cause traumatic localized infection (cellulitis, abscess and osteomyelitis), infection of the surgical wound, post-injection disease and disease related to intravascular catheters (Sungkanuparph et al., 2003; Lalitha et al., 2004; Regnier et al., 2009).

It is increasingly recognized as a rare but significant cause of chronic pulmonary infection in immune competent patients but more commonly causes infections 
of the skin and soft tissue(Todd et al.,. 2000; BrownElliott and Wallace., 2002).

Furthermore, it has been reported among individuals with chronic lung diseases, such as tuberculosis-old chronic obstructive pulmonary disease and cystic fibrosis to be prone to lung infections M.chelonae (Koh et al., 2007).

M.chelonae one of the most pathogenic RGM showing increased resistance to antibiotics (Regnier et al., 2009). The differences in susceptibility patterns of species and resistance to first-line antituberculosis drugs create challenges in the approach to treatment of these organisms (Mart'in-Casabona et al., 2004).

$M$. chelonae is resistant to antituberculosis agents but is susceptible to a number of traditional antibacterial agents (Nash et al., 2009). Although amikacin, tobramycin, clarithromycin, linezolid, imipenem, ciprofloxacin, levofloxacin, doxycycline, and azithromycin are considered to be effective (Wallace et al., 2001).

We therefore studied the frequency of $M$. chelonae, identification of these bacteria, obtained from Patients with Suspected Tuberculosis, during a twelve months period. Then testing drug susceptibility to antibiotics.

\section{Methodology}

\subsection{Sample Collection and Processing}

This study included the isolation of $M$. chelonae from 150 samples from patients attended to the ACCDR, during nine months period (March to November 2013).Three sputum specimens and a thick-yellow pleural fluid sample were collected. All sputum samples $(10 \mathrm{ml})$ were collected with sterile screw cap containers in the early morning. Expectorated sputum was taken by asking the patient to cough deeply into the container, followed by screwing of the cap immediately. Samples were transported to the laboratory within two hours and processed immediately or refrigerated at $4^{\circ} \mathrm{C}$ as soon as possible(Sireva, 1998).

\subsection{Microbiologic Examination}

The specimens were processed on the same day for microscopy and culture using standard procedures (Koneman et al., 1997).

The smears were stained with Ziehl Neelsen (ZN). Samples were inoculated into Lowenstein Jensen (LJ) medium after decontamination procedures and concentration, then incubated at $37^{\circ} \mathrm{C}$. The cultures were examined every day for a week, then once a week for eight weeks. The isolates were obtained in a week confirmed as acid-fast bacilli by ZN staining identification to species level was achieved on the basis of the growth characteristics, including growth in less than 7 days, growth at $37^{\circ} \mathrm{C}$, growth in presence of $\mathrm{NaCl} 5 \%$, pigment production, Niacin production, pyrazinamidase, urease, nitrate reduction test, catalase test, heat-stable catalase (pH 7, 68 ${ }^{\circ} \mathrm{C}$ ), Tween 80 hydrolysis, growth on MacConkey agar, arylsulfatase test, and colony morphology (Miyamoto et al., 2006).

\subsection{Susceptibility Tests}

The in vitro antimicrobial susceptibility of $M$. chelonae was tested using proportional method (Canetti et al., 1963). It were tested to antibiotics (Rifampicin $(1 \mu \mathrm{g} / \mathrm{ml})$, Ethambutol (2 $\mu \mathrm{g} / \mathrm{ml})$, Pyrazinamide $(0.25 \mu \mathrm{g} / \mathrm{ml})$, Isoniazid $(0.2 \mu \mathrm{g} / \mathrm{ml})$, Streptomycin $(2 \mu \mathrm{g} / \mathrm{ml}))$.

The results must be reading after three weeks of incubation at $35^{\circ} \mathrm{C}$. The strain was recorded as resistant when growth on antibiotic containing medium was more than the growth on the medium without antibiotic. When the case was opposite, the strain was considered as susceptible. The resistance percent was calculated according to Vestal 1975.

\section{Results}

The sputum samples of 150 suspected TB patients (73 male and 77 female) aged from 10 -80 years, the data are shown in Table 1.

Table 1. The clinical features of four patients infected with $M$. chelonae

\begin{tabular}{|c|c|c|c|c|}
\hline Case No. & Age(Yrs) & Sex & Case Type & Work Type \\
\hline 26 & 43 & M & Follow up & Earner \\
\hline 48 & 60 & F & New & House wife \\
\hline 76 & 51 & F & New & House wife \\
\hline 114 & 25 & F & New & House wife \\
\hline
\end{tabular}

\subsection{Microbiologic Examination Results}

The direct microbiologic examination results of $M$. chelonaes howed acid-fast, gram-positive and acid fast bacilli, pleomorphic rods and non-sporulating and measured 2-7 $\mu \mathrm{m}$ x $0.2-0.5 \mu \mathrm{m}$ (Figure 1).

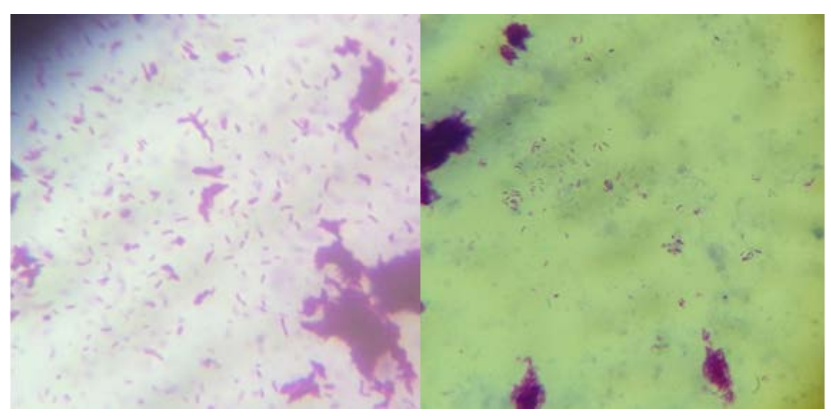

Figure 1. Direct examination of $M$. chelonae on ZN stain

The colonies of $M$. chelonae on LJ medium was circular, smooth, pale-cream colonies (Figure 2). The biochemical and growth characteristics results are summarized in Table 2.

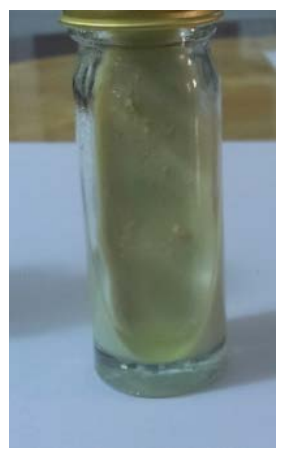

Figure 2. circular, smooth, pale-cream M. chelonae colonies on LJ medium 
Table 2. Summarized results of biochemical tests $M$. chelonae

\begin{tabular}{|c|c|}
\hline Test or property & M. chelonae \\
\hline Growth at $37^{\circ} \mathrm{C}$ & + \\
\hline Growth in less than 7 days & + \\
\hline Pigment in dark & - \\
\hline Photoreative pigment & - \\
\hline Nitrate reduction & + \\
\hline Growth on McConkey agar & + \\
\hline Niacin production & - \\
\hline Growth in presence of NaCl 5\% & + \\
\hline Arylsulfatase (3 days) & + \\
\hline Tween 80 hydrolysis & - \\
\hline Pyrazinamidase & - \\
\hline Urease & - \\
\hline Heat stable catalase &
\end{tabular}

\subsection{Susceptibility Tests Results}

Drug susceptibility results showed all isolates $M$. chelonae resistance to rifampicin, while one isolate showed intermediate resistance to ethambutol. all isolates of $M$. chelonae were sensitive to pyrazinamide, isoniazid and streptomycin. The antimicrobial susceptibility result summarized in Table 3.

Table 3. Antimicrobial susceptibility result of four $M$. chelonae isolates from patients

\begin{tabular}{|c|c|c|c|c|}
\hline Antimicrobial agent & \multicolumn{4}{|c|}{ M. chelonae } \\
\hline Number of Isolates & 26 & 48 & 76 & 114 \\
\hline Rifampicin & $\mathrm{R}(50 \%)$ & $\mathrm{R}(96 \%)$ & $\mathrm{R}(44 \%)$ & $\mathrm{R}(14 \%)$ \\
\hline Ethambutol & $\mathrm{S}$ & $\mathrm{R}(4 \%)$ & $\mathrm{S}$ & $\mathrm{R}(2 \%)$ \\
\hline Pyrazinamide & $\mathrm{S}$ & $\mathrm{S}$ & $\mathrm{S}$ & $\mathrm{S}$ \\
\hline Isoniazid & $\mathrm{S}$ & $\mathrm{S}$ & $\mathrm{S}$ & $\mathrm{S}$ \\
\hline Streptomycin & $\mathrm{S}$ & $\mathrm{S}$ & $\mathrm{S}$ & $\mathrm{S}$ \\
\hline
\end{tabular}

\section{Discussion}

A review of previously reported cases reveals that most patients with pulmonary infections due to $M$. chelonae are non immunosuppressed but have underlying chronic lung disease (Wallace et al., 2014). An unusual increased frequency of isolation of $M$. chelonae was noted (Xiang et al., 2007).

In summary, the results of this study showed that highfrequency of M.chelonae, represented $2.6 \%$ for all isolates. That indicator of increase of infections by this bacteria, and this agree with previous studies (Hazelton et al., 2000; Todd et al.,. 2000; Brown-Elliott and Wallace., 2002; Mateo et al., 2006; Tschiedel et al., 2006; David et al., 2007; Metta et al., 2008; Cortesia et al., 2010; Simons et al., 2011; Conaglen et al., 2013). The high frequency of M chelonae due to transmission by inhalation of aerosols or by inoculation, but normally it is not transmitted from person to person (Metta et al., 2008).

Previous study has shown that $M$. chelonae can cause transient colonization as well as pulmonary infection in patients who have undergone bronchoscopy with contaminated equipment (Pappas et al., 1983). Although M. chelonae pulmonary disease has not developed in any of the patients, all patients should be followed (Wang et al., 1995).

According to our study of pulmonary $M$. chelonae infection, three of four patients were middle-aged or elderly women (mean 45 years) and one case was male (43 year), and this agree with Hazelton et al 2000.

On the other hand, results of susceptibility of antibiotics, M. chelonae isolates showed resistant or partially susceptible to many antituberculous drugs and this agree with previous studies (Wallace et al., 1992; Brown-Elliott and Wallace., 2002; Regnier et al., 2009; Shaaban et al., 2012).

A treatment strategy for complicated pulmonary diseases has not yet been established. Only one clinical trial on the successful treatment of $M$. chelonae skin infection used clarithromycin (Wallace et al., 1993). Over the last several decades, the bacterial resistant to antibiotics becoming global challenge.

Although the optimal duration of therapy is not well defined, treatment for a minimum of 12 months of sputum- negative patients should be considered (Griffith et al., 2007). However, in Iraq we need to focus on the identification and treatment strategies for $M$. chelonae and other NTM especially in pulmonary diseases, and still needs more prospective studies for reference.

\section{Conclusions and Recommendations}

This paper has documented the isolation of M. chelonae from human sputum. the focus is always on the TB bacteria to their importance and the increasing mortality rates of infection. We find that other types of causing symptoms similar to tuberculosis, such as $M$. chelonae require real pause and reconsider the methods of diagnosis and then a change in the therapeutic regimes depending on the ability of bacteria to resist.

\section{Reference}

[1] Al-Sulami A.A., Al-Taee A. M. and Widaa Q. 2012. Isolation and Identification of Mycobacterium avium complex and other non tuberculosis mycobacteria from drink water in Basra government, Iraq. East Mediter Health. J. 18 (3): 274-278.

[2] Brown-Elliott BA, Wallace RJ Jr, Onyi GO. 1992. Activities of four macrolides, including clarithromycin, against Mycobacterium fortuitum, Mycobacterium chelonae, and $M$. chelonae-like organisms. Antimicrob Agents Chemother. 36: 180-184.

[3] Brown-Elliott BA, Wallace RJ Jr. 2002. Clinical and taxonomic status of pathogenic nonpigmented or late-pigmenting rapidly growing mycobacteria. Clin Microbiol Rev. 15: 716-46.

[4] Brown TH. 1985. The rapidly growing mycobacteria Mycobacterium fortuitum and Mycobacterium chelonei. Infect Control. 6: 283-288.

[5] Canetti G, Froman S, Grosset J. 1963. Mycobacteria: Laboratory Methods for Testing Drug Sensitivity and Resistance. Bull Wld Hlth Org. 29: 565-578.

[6] Conaglen PD, Laurenson IF, Sergeant A, Thorn SN, Rayner A, Stevenson J. 2013. Systematic review of tattoo-associated skin infection with rapidly growing mycobacteria and public health investigation of a cluster in Scotland, 2010. Euro Surveill. 18 (32): $1-13$.

[7] Cortesia C. , Lopez G. J. , de Waard J. H. , and Takiff H. E. · 2010. The use of quaternary ammonium disinfectants selects for persisters at high frequency from some species of non-tuberculous mycobacteria and may be associated with outbreaks of soft tissue infections. J Antimicrob Chemother. 65 (12): 2574-2581.

[8] David E. Griffith, Timothy Aksamit, Barbara A. Brown-Elliott, Antonino Catanzaro, Charles Daley, Fred Gordin,Steven M. Holland, Robert Horsburgh, Gwen Huitt, Michael F. Iademarco, Michael Iseman, Kenneth Olivier, Stephen Ruoss, C. Fordham von Reyn, Richard J. Wallace, Jr., and Kevin Winthrop, 2007. An Official ATS/IDSA Statement: Diagnosis, Treatment, and Prevention of Nontuberculous Mycobacterial Diseases. AMERICAN JOURNAL OF RESPIRATORY AND CRITICAL CARE MEDICINE. 175: 367: 415. 
[9] Falsey RR, Kinzer MH, Hurst S. 2013. Cutaneous inoculation of nontuberculous mycobacteria during professional tattooing: a case series and epidemiologic study. Clin Infect Dis. 57: 143-147.

[10] García-Agudo L. and García-Martos P. 2011. Clinical significance and antimicrobial susceptibility of rapidly growing mycobacteria. Science against microbial pathogens: communicating current research and technological advances. A. Méndez-Vilas (Ed.): 363: 377.

[11] Grange JM. 1981. Mycobaterium chelonei. Tubercle. 262: 273.

[12] Griffith DE, Aksamit T, Brown-Elliott BA, Catanzaro A, Daley C, Gordin F.2007. An official ATS/IDSA statement: diagnosis, treatment, and prevention of nontuberculous mycobacterial diseases. Am J RespirCrit Care Med. 175: 367-416.

[13] Hazelton, T. R., Newell, J. D., Cook, J. L., Huitt, G. A. \& Lynch, D. A. 2000. CT findings in 14 patients with Mycobacterium chelonae pulmonary infection. AJR Am J Roentgenol 175. 413416.

[14] Koh WJ, Lee JH, Kwon YS. 2007. Prevalence of gastroesophageal reflux disease in patients with nontuberculous mycobacterial lung disease. Chest. 131: 1825-1830.

[15] Koneman EW, Allen SD, Janda WM, Schreckenberger PC, Winn WC JR. 1997. Colour atlas and textbook of diagnostic Microbiology. 5 th ed. JB Lippincot Company.: 897-906.

[16] Lalitha P, Rathinam SR, Srinivasan M. 2004. Ocular infections due to non-tuberculous Mycobacteria. Indian Journal of Medical Microbiology. 22: 231-237.

[17] Mart'n-Casabona, N.; Bahrmand,A.R.; Bennedsen, J. 2004. Nontuberculous mycobacteria: Patterns of isolation. A multicountryretrospective survey. International Journal of Tuberculosisand Lung Disease. 8 (10: 1186-1193.

[18] Mateo L, Rufí G, Nolla JM, Alcaide F. 2004. Mycobacterium chelonae tenosynovitis of the hand. Semin Arthritis Rheum. 34: 617.

[19] Metta H., Corti M. and Brunzini R. 2008. Disseminated Infection Due to Mycobacterium chelonae with Scleritis, Spondylodiscitis and Spinal Epidural Abscess. The Brazilian Journal of Infectious Diseases. 12 (3): 260-262.

[20] Miyamoto, Y., Mukai, T., Nakata, N., Maeda, Y., Kai, M., Naka, T., Yano, I. \& Makino, M. 2006. Identification and characterization of the genes involved in glycosylation pathways of mycobacterial glycopeptidolipid biosynthesis. J Bacteriol. 188: 86-95.

[21] Nash KA, Brown-Elliott BA, Wallace RJ Jr. 2009. A novel gene, erm (41), confers inducible macrolide resistance to clinical isolates of Mycobacterium abscessus but is absent from Mycobacterium chelonae. Antimicrob Agents Chemother. 53: 1367-1376.

[22] Pan America health organization regional systems for vaccines (SIREVA). Streptococcus pneumoniae and Haemophilus influenzae identification and susceptibility testing. Proceedings of the Insituto Nacional de Saluda; Nov 23-Dec 1; Santa Fe de Bogota, 1998.

[23] Pappas SA, Schaaf DM, DiCostanzo MB, King FW, Sharp JT. 1983. Contamination of flexible fiberoptic bronchoscopes. Am Rev Respir Dis. 127: 391-392.

[24] Regnier S, Cambau E, Meningaud JP, Guihot A, Deforges L, Carbonne A, Bricaire F and Caumes E. 2009. Clinical management of rapidly growing mycobacterial cutaneous infections in patients after mesotherapy. Clinical Infectious Diseases. 49: 1358-1364.

[25] Sethi NK, Aggarwal PK, Duggal L and Sachar VP. 2003. Mycobaterium chelonei infection following laparoscopic inguinal herniorrhaphy. JAPI. 51: 81.

[26] Shaaban H. S, Bishop S. L, Menon L., Slim J. 2012. Mycobacterium chelonae infection of the parotid gland: 4 (1): 7981.

[27] Simons S., Ingen J. v., Hsueh P., Hung N. V., P.N., Dekhuijzen R.,Boeree M. J., and Soolingen D. 2011. Nontuberculous Mycobacteria in Respiratory Tract Infections, Eastern Asia. Emerging Infectious Diseases. 17 (3): 343-349.

[28] Sungkanuparph S, Sathapatayavongs B, Pracharktam R.2003. Infections with rapidly growing mycobacteria: report of 20 cases. International Journal of Infectious Diseases.7: 198-205.

[29] Talip B. A., Sleator R. D. , Lowery C. J., Dooley J. S.G., and Snelling W. J. 2013. An Update on Global Tuberculosis (TB). Infect Dis. 6: 39-50.

[30] Todd R. Hazelton1, John D. Newell, Jr., James L. Cook3, Gwen A. Huitt and David A. 2000. Lynch1CT Findings in 14 Patients with Mycobacterium chelonae Pulmonary Infection. American Journal of Roentgenology. 175 (2): 413-416.

[31] Tschiedel E. Grasemann H. Ratjen F. 2006. Mycobacterium chelonae in a CF patient with anaplastic large cell lymphoma. Journal of Cystic Fibrosis. 5 (2): 133-136.

[32] [Vestal, A. L. 1975. Procedures for the isolation and identification of mycobacteria. U.S. Department of Health, Education and Welfare publication no. (CDC) 76-8230; 97-115. Center for Disease Control, Atlanta.

[33] Wali S. 2009. Mycobacterium chelonae empyema with bronchopleuralfistula in an immunocompetent patient. Annals of Thoracic Medicine. 4 (4): 213-215.

[34] Wallace RJ Jr, Brown BA, Onyi GO. 1992. Skin, soft tissue, and bone infections due to Mycobacterium chelonae: importance of prior corticosteroid therapy, frequency of disseminated infections, and resistance to oral antimicrobials other than clarithromycin. $\mathrm{J}$ Infect Dis. 166: 405-12.

[35] Wallace RJ Jr., Dukart G., Brown-Elliott B. A., Griffith D. E. , Scerpella E. G. and Marshall B. 2014. Clinical experience in 52 patients with tigecycline-containing regimens for salvage treatment of Mycobacterium abscessus and Mycobacterium chelonae infections. J Antimicrob Chemother. 69 (7): 1-9.

[36] Wallace, R. J., Jr, Tanner, D., Brennan, P. J. \& Brown, B. A.1993. Clinical trial of clarithromycin for cutaneous (disseminated) infection due to Mycobacterium chelonae. Ann Intern Med 119, 482-486.

[37] Wallace RJ Jr, Brown-Elliott BA, Ward SC. 2001. Activities of linezolid against rapidly growing mycobacteria. Antimicrob Agents Chemother. 45: 764-767.

[38] Wang H.C., Liaw Y.S, Yang P.C., Kuo S.H. and Luh K.T. 1995. A pseudoepidemic of Mycobacterium chelonae infection caused by contamination of a fibreoptic bronchoscope suction channel. Eur. Respir. J. 8: 1259-1262.

[39] Xiang Y. Han, MD, PhD, Indra DE, MD, PhD, Kalen L and Jacobson, MD. 2007. Rapidly Growing Mycobacteria: Clinical and Microbiologic Studies of 115 Cases. Am J ClinPathol. 128 (4): 612-621. 